\title{
Ranting in 2019: Are Things Improving?
}

\author{
Irl B. Hirsch, MD \\ "When somebody challenges you, fight back. Be brutal, be tough." \\ -Donald Trump
}

\begin{abstract}
A S I CONSIDER these words of wisdom from our current president for this annual rant, I have to wonder if this is our problem. As a group of health care professionals, are we too passive? Do we need to be more pugilistic as suggested? Does this also mean we should take away the compassion and caring that defines our profession? That would certainly define our world today.

In this my sixth rant, I reminisce about my previous cathartic writings, reviewing various cases, situations, and predicaments our medical system has created. Most of these were simply commentaries about where our situation is so dysfunctional. In subsequent e-mails I have been called everything from a whiner to an ingrate. I acknowledge there must be some truth to this. Just thinking how fortunate we are compared with our ancestors not having to worry about pandemics such as The Great Plague, Smallpox, or the Spanish flu, where a significant percentage of the population died. Childhood mortality in the United States is now $<1 \%$, compared with about a third dying before adulthood a century ago, mostly from malnutrition and infectious disease. ${ }^{1}$ The introduction of antibiotics and insulin in the past century has changed the world forever and for many of us has allowed us not only to survive but lead productive lives. According to lifexpectancy.com, in 2016, the average American could expect to live to be 78.5 years. That is almost a decade more than the life expectancy in 1960! But to me, this statistic is not as wonderful as it seems. In 1960, globally the United States ranked 16th in mortality. Fifty-six years later we have fallen to 34th (for the record, our neighbors to the north of us in Canada, where $20 \%$ of my patients purchase their insulin, ranked 7th in 2016), which in my mind gives me license to write this year's rant without apology.
\end{abstract}

My first patient is a 69-year-old man with type 2 diabetes on basal-bolus insulin therapy who has survived decades of diabetes, chronic kidney disease, and a myocardial infarction. We documented 2 years ago he was having much more hypoglycemia than he appreciated with a professional continuous glucose monitor (CGM). With the approval of CGM devices by Medicare, it was now possible for him to minimize his hypoglycemia. But to get Medicare approval, he had to be testing his blood glucose four times a day. Going back through his finger-stick downloads, I noted that most of the time he was checking 3.5-4 times daily despite my encouragement for more. I explained to him at his visit he needed to get to a minimum of four tests per day to qualify for a personal CGM. "No problem!" he said enthusiastically.

The next month he brought his meter in for a download. The paperwork for Medicare was completed and submitted. Three weeks later the application was denied by the distributor. I was perplexed because all of the wording in the note was correct, I documented his multiple daily injections, and he was testing four times daily. What did I do wrong? The answer is nothing: his download showed he had 3.9 tests per day, not 4.0. So, I was even more confused. Does Medicare "round down" when it comes to home blood glucose monitoring? The answer was this is not about Medicare, it is about this one distributor. Its policy is if it is not 4.0 or above, it does not want to risk an audit from our friends at the Centers for Medicare and Medicaid Services (CMS). My protest was to no avail. The story, however, has a happy ending. I had the patient come in the next day and download late in the afternoon instead of first thing in the morning. Those extra two tests that day allowed the download statistics to tick up to 4.0, and he was able to get his CGM.

Speaking of Medicare distributors, it is interesting how their personalities differ widely. I have been seeing a 75-yearold woman who had diabetes since the early 1960s. She became completely blind in 1982, just as the era of home blood glucose monitoring was starting. She has been widowed for only 2 years, but amazingly she remains independent and lives alone. She uses a "talking" home blood glucose monitor, which works great for her, but unfortunately it is not downloadable. To her credit, she is able to scribble her glucose levels on a small note pad, which are readable (by me anyway).

Like clockwork, within $24 \mathrm{~h}$ after her visit with me I receive a fax from the distributor demanding evidence of her home blood glucose monitoring frequency, so she can continue to receive her blood glucose test strips. My attestation is

University of Washington School of Medicine, Division of Metabolism, Endocrinology, and Nutrition, Seattle, Washington. 
not enough. There needs to be visual evidence! Her scribbles on her notepad are not adequate since they are barely legible, so by default I have to have a medical assistant or office secretary take each scribble and enter it into a spreadsheet. And this distributor wants to see 3 months of data! All in all, this takes hours to do, for each visit. I have tried to talk to the distributor, but "rules are rules," I was told several years ago. This patient is not able to use CGM, and in my mind, she should be put on a pedestal for every health care professional and person with type 1 diabetes. Instead, CMS and this one distributor do what they can to make her (and my clinic's) life more difficult.

I do not want to lose sight that we are fortunate that CGM is covered for those Medicare beneficiaries who are receiving multiple injections of insulin or who are on insulin pump, and as noted earlier, who are measuring their blood glucose at home at least four times daily. Still, our commercial payers are not as enlightened. In late December I received a CGM denial form from one of our country's largest payers that noted "the services (CGM) are not eligible for coverage because the plan does not cover unproven procedures. To be considered proven, services must be recognized as safe and effective....according to clinical evidence published in peerreviewed journals." Ironically, this was one of the first payers for CGM more than a decade ago, but that was for type 1 diabetes. This is a patient with long-standing type 2 diabetes. Admittedly, there are not as much data for type 2 diabetes as we see with type 1 diabetes, but the randomized trials for the former show effectiveness. ${ }^{2,3}$ It is my view that for appropriate patients (all insulin-requiring patients), we should not need to continue appealing our case.

And what is a yearly rant without a mention of our electronic medical record (EMR)? I have complained about this in the past, but this topic never gets repetitive. This year's story is a 66-year-old man I have been seeing for $>25$ years. He has type 1 diabetes, and when I saw him, he was failing his kidney transplant from a decade earlier. He unfortunately is blind with bilateral amputations. When I saw him, I was concerned about a pending infection, as his blood pressure was low and he was short of breath while receiving immunosuppression. I sent him to the emergency room, and he died 2 days later, septic from pneumonia. All things considered, he lived a good life, and his family was grateful for my years of caring for him.

But the problem has to do with the EMR. For this renal patient without feet or eyesight, I had failed to examine his feet (he was not wearing his prothesis on this day, but I'm not sure how helpful the examination would have been), nor had I sent him to the eye doctor for which, according to the calendar in the EMR, he was past due (by $>5$ years since he was discharged from the eye clinic). The good news is he met blood pressure criteria (since one cannot get penalized for hypotension), but that is only because he was essentially in septic shock at the time. So at least the administrator who "grades" me will be happy not only did his blood pressure "pass," but $12 \mathrm{~h}$ later he was on a pressor.

In my humble view, metrics for quality of care are important and likely will become an even more critical part of our health care system. But how can we continue to give all patients (with or without diabetes) similar performance metrics? In the world of diabetes, an 18-year-old man with 2 years of type 1 diabetes has the same treatment targets and complication screening criteria as a 35 -year-old woman with lymphoma on high-dose steroids, a 50-year-old man immediately postpancreatectomy for pancreatic cancer, a 63-yearold woman with 5 years of type 2 diabetes, and a 70-year-old man with 60 years of type 1 diabetes. Even the U.S. senator who thinks people with diabetes should be responsible for their own health care costs due to living unhealthy lifestyles-even HE would realize this makes no sense. But this is where we are.

And now it is time to rant about my colleagues-no, not endocrinologists, but certain surgeons who refuse to operate for an elective surgery unless the A1C is below " $X$," with " $\mathrm{X}$ " being that number seemingly pulled out of the air by that surgeon. Do not get me wrong-some of my best friends are surgeons (and I hope they are reading this) and like many, I am grateful for their expertise for me and my family over the years. But why does my 61-year-old man with 45 years of type 1 diabetes need to have an $\mathrm{A} 1 \mathrm{C}<7 \%$ to have his foot surgery, or my 72-year-old woman with 10 years of type 2 diabetes need to have her $\mathrm{A} 1 \mathrm{C}<6.5 \%$ for her knee replacement? Where is the American College of Physicians when you need them? ${ }^{4}$ I have not been able to educate my colleagues about the wide variation in blood glucose levels for any A1C level and how with CGM we can now use the glycemic management indicator. ${ }^{5}$ Most important, the data do not support these low levels of A1C for surgical outcomes. For example, in one review of $>40,000$ knee surgeries, which included $>7500$ patients with diabetes, there was no relationship with surgical outcomes and diabetes, no matter the A1C. ${ }^{6}$ Another study did show a relationship between preoperative $\mathrm{A} 1 \mathrm{C}>8 \%$ and hospital length of stay in noncardiac surgical procedures. ${ }^{7}$ At the very least, the literature is not conclusive on this point, but more importantly speaks to our need for more education for our surgical colleagues (and perhaps everyone) about the limitations of A1C. ${ }^{8}$ It would also be helpful for those operating on our geriatric patients who require insulin to appreciate the potential dangers of hypoglycemia in this population.

And there needs to be a comment about our new longacting insulin analogs. No matter what hospital formulary chair tells me, insulin degludec, U300 glargine, U100 glargine, and detemir are not interchangeable. I have not yet seen the first two of these analogs on any inpatient formulary even though more of our patients are using these newer insulins. Patients are admitted to community hospitals where the wellintentioned hospitalists have never even heard of these new insulins (except possibly from television commercials). I cannot even count how many times I have seen the bedtime degludec reduced by $50 \%$ the night before a procedure (usually a colonoscopy). I guess I should be grateful that only two of my patients developed iatrogenic ketoacidosis from the unfamiliarity of these insulins with our colleagues. My main gripe is that many hospitals will not even consider putting degludec or U300 glargine on their hospital formulary since these insulins are only available in pens, and I am told the education required to move these hospitals from vials is insurmountable, at least for some hospitals. We definitely need consensus on how to deal with this important topic. Up until now my screaming has not been heard.

And for the record for my friends in Indianapolis, Paris, and Copenhagen, I totally understand insulin is not an exception and that in the U.S. drug price increases are the rule 
(and above the rate of inflation). As we enter 2019, we are told that more than three dozen drug makers have raised the prices on hundreds of drugs. ${ }^{9}$ The average increase is $6.3 \%$ although one company (no, they do not manufacture insulin) raised 27 products by $9.5 \%$. Although insulin prices do not appear to be rising this quickly, there are few American patients celebrating the affordability of their insulin.

Finally, I need to mention my experience at a regional continuing medical education (CME) conference this year. Several days before the conference, I was asked to give a second talk, as one of the other speakers had a family emergency and could not attend. I was happy to assist and presented the current state of insulin costs in the United States. In the audience was a physician who was attending specifically for the thyroid talks, as he is a thyroid surgeon. He also acknowledged he has no expertise in diabetes. Still, he was quite upset at the content presented, and afterward gave me a piece of paper that I have kept and read many times.

He was quite angry. Comments written included "have you eliminated all of your pharma stocks from your 401K" and "how much charity care do you provide?" He was also upset (at me) about the data presented on insulin rationing ${ }^{10}$ and the deaths caused by unaffordable insulin. He maintained that the increase in diabetic ketoacidosis from 2009 to 2014 was a result of the Affordable Care Act (recall, he acknowledged he is not a diabetes expert), and I was implying we need to move to "Socialized Medicine" since I gave no other practical solutions to the insulin cost crisis. I was also told I was spreading "propaganda.",

I doubt most people reading this rant would agree with this surgeon, but perhaps I am mistaken. What is clear to me is that there is much ignorance within the medical community, which is driven by political ideology. Should not the entire medical community be demanding solutions? How can Mr. (ok, Dr.) Thyroid ignore facts and reason such as many other political debates? This is just one more example where data and truths are overshadowed by a basic human need (insulin for type 1 diabetes). This is not about politics. Americans are now literally dying because they cannot afford insulin. Perhaps Mr. Thyroid would be more understanding if there were data supporting that global warming resulted in more thyroid cancer, but we will need to wait for that analysis. At the very least I hope he answered the two CME post-test questions correctly, so he could receive his $1 \mathrm{~h}$ of credit from my talk.

Another year, another temper tantrum. But is our system improving and are patients receiving more efficient health care with greater value? The answer is mixed. For type 1 diabetes, the routine use of CGM has revolutionized therapy. For those with type 2 diabetes, the positive cardiovascular outcome trials (with positive renal secondary endpoints) with the GLP1 receptor agonists and SGLT2 inhibitors will likely make major impacts in the morbidity and mortality seen with this disease. Still, we all continue to shake our heads at how difficult it is to work in this system, ensuring as many people have access to all of our medical discoveries and expertise. I do not want to read about another death from ketoacidosis due to unaffordable insulin. Each year I wonder if there will be any reason to rant the next year. That is one question I'm sure I can answer: I have no doubt there will be a 2020 rant.

\section{References}

1. https://ourworldindata.org/child-mortality (accessed December 29, 2018).

2. Beck RW, Riddlesworth TD, Ruedy K, et al: Continuous glucose monitoring versus usual care in patients with type 2 diabetes receiving multiple daily injections: a randomized trial. Ann Intern Med 2017;167:365-374.

3. Haak T, Hanaire H, Aijan R, et al.: Flash glucose-sensing technology as a replacement for blood glucose monitoring for the management of insulin-treated type 2 diabetes: a multi-center, open-label, randomized controlled trial. Diabetes Ther 2017;8:55-73.

4. Draznin B, Nathan DM, Korytkowski MT, et al.: Guidelines versus guidelines. Ann Intern Med 2018;169:896897.

5. Bergenstal RM, Beck RW, Close KL, et al.: Glucose Management Indicator (GMI): a new term for estimating A1C from continuous glucose monitoring. Diabetes Care 2018;41:2275-2280.

6. Adams AL, Paxton EW, Wang JQ, et al.: Surgical outcome of total knee replacement according to diabetes status and glycemic control, 2001-2009. J Bone Joint Surg Am 2013; 95:481-487.

7. Underwood P, Askari R, Hurwitz S, et al.: Preoperative A1C and clinical outcomes in patients with diabetes undergoing major noncardiac surgical procedures. Diabetes Care 2014;37:611-616.

8. Rubinow KB, Hirsch IB: Reexamining the metrics for glucose control. JAMA 2011;305:1132-1133.

9. Hopkins JS: Drug makers raise prices on hundreds of medicines. Wall St J January 1, 2019.

10. Herkert D, Vijayakumar BA, Luo J, et al.: Cost-related insulin underuse among patients with diabetes. JAMA Intern Med 2019;179(1):112-114. DOI: 10.1001/jamainternmed .2018 .5008 .

Address correspondence to: Irl B. Hirsch, $M D$

University of Washington School of Medicine 4245 Roosevelt Way NE, 3rd Floor Seattle, WA 98105

E-mail: ihirsch@uw.edu 